\title{
The Perceptions of Parents AND Caregivers on the Causes of Disabilities in ChILDREN With CEREBRAL PALSY: A QualitaTiVe INVESTIGATION
}

\begin{abstract}
The purpose of this study was to investigate the perceptions of parents and caregivers on the causes of disabilities in children with cerebral palsy in selected areas of the Cape Metropolitan. A qualitative research design was chosen for the investigation. Data collection was by semi-structured interviews. The results showed that the range of variation in the beliefs of the parents and caregivers concerning the cause of the child's disability and the stigma attached was quite considerable. However, the majority of the informants hardly knew the causes of disabilities while only a few informants seemed to have known. It is

MWESHI, MM, DIP. PT (Zambia), MSc. PT (UWC)'; MPOFU, R, MCSP, DIP TP, MSc Rehabilitation (UK), PhD (UWC) ${ }^{2}$

1 Francis Sisters, Luanshya, Zambia.

2 Dean, Department of Physiotherapy, University of the Western Cape recommended that health professionals who work with families directly could play a major role in preventing unnecessary stressful situations by providing adequate information about the child's condition in terms of aetiology and the likely prognosis. Helping and working with such families require a multidisciplinary effort, effective communication among families and professionals, and knowledge of community resources.
\end{abstract}

\section{KEY WORDS: CAREGIVING, CEREBRAL PALSY, DISABILITY, NATURALISTIC, PERSONALISTIC}

\section{INTRODUCTION}

Cerebral palsy is one of the common causes of severe physical disabilities in children caused by irreversible brain lesions occurring before, during or shortly after birth. It affects the motor and often, other systems controlled by the brain. The associated handicaps may include speech, language problems, oral-dental problems, visual, cognitive and hearing impairments, and behavioural problems (Pimm, 1996).

The definition of disability has been the subject of many debates resulting in the development of the International Classification of Impairments, Disabilities and Handicap (ICIDH) followed by the $\mathrm{ICIDH}-2$ which is now being field tested (WHO 1980, 1997). The general understanding is that a multipurpose classification must be designed

\section{CORRESPONDENCE TO:}

Mrs R. Mpofu

Department of Physiotherapy,

University of the Western Cape,

Private Bag X17,

7535 Bellville

South Africa for use in different settings and to provide a common framework for understanding the dimensions of disablement and functioning at three different levels: the body, the person, and society. Studies have shown that in the health sector, diagnosis alone does not predict needs, length of hospitalisation, level of care nor outcomes. However, when data on functioning are taken into account the predictive power and understanding of needs and outcomes are increased.

Medical anthropologists (Leavitt, 1992) have defined a medical care system as the constellation of beliefs, knowledge, practices, personnel, facilities and resources that together structure and pattern the way members of a sociocultural group obtain care and treatment of illness. Others use the term comparative ethno-medicine as those beliefs and practices relating to disease which are products of indigenous cultural development and are not explicitly derived from the conceptual framework of modern medicine (Leavitt, 1992). Kleinman (1980) has developed one process of medical ethnography, through which local health care systems are analysed. The process analyses issues like, patterns of beliefs about causes of illnesses, decisions about how to respond to specific episodes of sickness and actions taken in order to effect a change employed by all those engaged in the clinical process. The analyses can be applied for a specific illness to address questions about five major factors: aetiology, time and mode of onset of symptoms, patho-physiology, causes of sickness and treatment. The answers to these questions can be formed by the patient, family and health professionals and can be used in response to a particular illness or condition.

Reis (1992) points out that causality beliefs also determine the way lay and professional people explain, treat and handle disability, and consequently their explanatory models and illness beliefs. Within traditional medicine, the primary concern is why a disability has been caused and in modern medicine how a disability is caused. Scholars use various terms to describe etiological theory, for example naturalistic-personalistic theories (Foster \& Anderson, 1978). In traditional communities a naturalistic cause of disablement is explained in impersonal systemic terms. In personalistic terms disablement is believed to be 
caused by purposeful interventions of a sensate agent who may be a supernatural being (such as a ghost, ancestor, or evil spirit), or human being (a witch or sorcerer). The disabled person is seen as the victim, the object of aggression or punishment directed specifically against him/her (Foster \& Anderson, 1978). Reis (1992) heeds that causality belief is not a static thought system, but a dynamic process that reflects the changes in society.

\section{PROBLEM STATEMENT}

Health professions managing children with disabilities tend to concentrate more on the physical limitations and medical problems ignoring the many diverse factors affecting the family members. Factors like cultural practices, beliefs and values, language, rearing, environment and socio-economic status of a family and community are known to influence care given to an individual in the caregiving environment. There is a need to help the professionals to understand and deal with the impact of disablement on the functioning of the disabled child, the siblings, caregivers and parents in the caregiving environment. Thus the perceptions of parents and caregivers on the causes of disabilities in children with cerebral palsy need to be explored.

\section{AIM OF THE STUDY}

The aim of the study was to investigate what family members perceived the causes of cerebral palsy to be and what the presence of a child with cerebral palsy meant in African and Coloured families in a selected area in South Africa so that a better understanding can be reached for better rehabilitation approaches to be implemented.

\section{SELECTION OF RESEARCH SETTING}

The researchers assume that there are sectors within the disabled community in South Africa which have experienced greater discrimination than others since South African society is still very discriminatory (White Paper on an Integrated National Disability Strategy, 1997). Society still regards children with disabilities as incapable, ill and a burden on it. According to the White Paper more than $80 \%$ of black (Africans, Coloureds and Indians) children with disabilities are said to live in extreme poverty. They lack education and live in environments which are not hospitable.

The purpose of this study was to investigate how parents and caregivers perceive causes of disabilities in the African and Coloured communities of selected parts of the Cape Metropolitan area. The area covers the cities of Cape Town and Tygerberg within which are a number of black (African and Coloureds) townships. The Red Cross and Tygerberg Physiotherapy Departments provide outreach programmes for children with cerebral palsy in some of the townships such as Gugulethu, Khayelitsha, Langa, Cross Roads, and Nyanga for the Africans families and through Bishop Lavis Rehabilitation Centre, Mitchell' Plain's Agape School and Special Care Centre for the Coloured families.

\section{METHODOLOGY}

A purposive sample of ten parents and caregivers of disabled children were recruited from physiotherapy out patients' departments of Tygerberg and Red Cross hospitals. The inclusion criteria for selecting parents/caregivers of disabled children were:

1. a child with cerebral palsy within the age-range of 1-18 years had to be living at home with the parent/caregiver

2. mild to moderately disabled clients who were capable of performing all aspects of personal care such as wash, dress, eat independently and selftoilet, with some assistance or none at all; and those who were severely disabled were dependant on parents/ caregivers or wheelchair bound.

After informed consent, they were interviewed with the help of two research assistants who were fluent in the local languages and in English. Some interviews were held in the homes of the disabled children with the family around and others in physiotherapy departments.

The semi-structured interviews were guided by the unique responses of the individual participants. They were asked to share

1. what they knew about the cause of disability in the child,
2. and parents were further asked to express if they felt responsible for the cause of disability.

For clarity the same issue was asked in various ways and intonation of voice and non-verbal communication was noted in order to confirm a true reflection of feelings. Assistants were instructed to use the local language in order to stress and clarify some of the issues. The interviews were recorded on tape and notes were taken during the interview.

The interviews were translated into English. The presentation tried as much as possible to retain the nuances. Occasionally the translations retained original words that would have been lost in the translation. Data were clustered and common variables were established. Comparative trends, tendencies and emphasis were noted and information in each interview was sorted into the predetermined themes and the new themes generated from the data.

\section{RESIULTS AND DISCUSSION}

The results and the discussion will be presented together in order to prevent repetition which often occurs in qualitative analysis. Transcribed verbatim excerpts from interview data will be quoted in numbers $\mathrm{Al}$ to $\mathrm{A} 10$ in order to protect the identity of children and families involved. The sample consisted of four mothers, two fathers and three relatives. Their ages ranged between fifteen and seventy years. Five came from the African and four from the Coloured groupings. Their children's ages ranged from one to thirteen years. The accounts constructed from the interviews are presented in such a way that the exact languages of the informants are preserved, although the order of the comments are sometimes altered.

The range of variation in the beliefs of the parents/caregivers concerning the cause of the child's disability and the stigma attached was quite considerable. The issue of stigma came out very clearly during interviews. Informants had their own way of expressing the stigma they undergo due to the presence of a disabled child in the family. Typically, the informants interviewed 
would preface their remarks with, "I don't know, but maybe", or there was some inconclusive evidence in that the informant might say, "I believe such and such, but my mother, husband or brother etc. thinks such and such." There was also a range of variation in the probable validity of the responses given. Examples of probable valid naturalistic causes of disability included: prolonged and difficult labour; jaundice and inherited abnormality.

Examples of responses that were oriented toward naturalistic belief systems included the following:

A2: It could have been jaundice ... the yellow stuff in your body. It must have been due to an accident I was involved in when I was at work during pregnancy.

A7: The mother of this child was very sick ... Everything got mixed up.

A8: The doctor told me that my sister's child had meningitis when she was born ... but I am not so sure because I was dealing with a very young doctor. I feel my sister had a shock ... because when she was in hospital, she heard that her husband had impregnated another woman whom he wanted to marry.'

A10: I always have children fast ... because I eat good food during pregnancy ... but this time ... I had no money because my husband lost his job and we have seven other children with two other dependants. The baby took a long time to be born.

In contrast to these beliefs were those in which the parent/caregiver believed in a supernatural or personalistic cause for the child's disability:

A5: There is a special wind produced by witches ... Every night I hear this wind and they take my grandchild with them to fetch other children.

Responding to the question, "Why did they choose your grandchild and not other children in the area?" She said,

It is because they are jealous of my family and me ... They think that my daughter who is the mother of the child is earning a lot of money. Other people say it is the magic that made him like that, but I think God gave him to me because He is testing my faith in Him. I am afraid of this magic and as such, our child is always indoors ... they might come to finish him.

A4: I am the father of the child and I believe in normal sickness with some addition of evil. It was the work of the devil ... When my wife was about to deliver, my aunt asked for some money and I explained to her that I had to take care of my baby's shopping ... You know what she said? You can keep your money but remember we shall meet in the graveyard. When the doctor told me that my baby had cerebral palsy ... I quickly remembered that my aunt cursed me.

Whether the parents/caregivers believed in a naturalistic or supernatural cause, there appeared to be a strong religious component to the belief system of many of them:

A2: I am a strong believer in God because $\mathrm{He}$ is the only one I can trust.

A3: I pray to God that my child can some day be able to walk ... He shall walk!

A1: I believe that He (God) made him in his own likeness just like any other person.

A5: Well, maybe He (Allah) knows that I can cope. I believe He cannot give you what you can't manage ... He always knows how to measure problems.

In contrast, a few people did not believe that God or Allah had any connection to their child's problems no matter what they believed was the cause of disability,

A6: $\mathrm{He}$ is love ... and therefore $\mathrm{He}$ cannot give me something bad ... It is the devil's work.

A7: He does not make anyone sick. Sickness is from the devil.

A8: I don't believe He ever gives a person anything not appealing. If someone is sick ... It is just natural.

A9: He made us in His own image and therefore disability is not from Him because $\mathrm{He}$ is perfect and what He makes is perfect.
Others had a negative attitude towards the creator:

A4: I am a Christian but the last time

I went to church was two years ago.

I have nothing to do there ... If God loved me, why did He give me a child who cannot do anything knowing that my wife cannot bear any child again? He is not fair... Why me and not somebody else?'

A10: I don't want to hear that He loves me ... Look at what He has done to my life and our family in general.

One of the parents felt completely responsible for the disability of the child as A3 said,

I am responsible for the disability of my child. ... my doctor told me that I was going to have twins but the life of the second was at stake if I didn't undergo an operation. I did not want to loose them both and thus decided to have it done. When I delivered... I got a shock of my life. One of my babies was disfigured and could not cry... and the other one was already dead...that was it... so who is to blame.

She also went on to explain how her husband had left her for another women in fear of having another disabled child ... He says there are no disabled people in his family and therefore it must have come from my family.

The findings of this investigation concur with other studies which have shown that in most cases parents do not know exactly what the causes of illness or disability are. A study done by Abrams and Goodman (1998) noted that professionals shield away from explicit use of labels, but prefer to use other descriptors to describe children's deficits and as such parents are see-sawed between optimistic and pessimistic statements. Other studies have shown that communicating bad news about children to parents who are unprepared for it is a complex and harsh task. The news giver is likely to cherish incompatible values: a desire to be candid and clear, and the wish to avoid hurting parents unduly (Adams, 1982). Similarly, the news receiver wants to receive both, that is to hear the truth, and yet likely to resist it (Lynch \& Staloch, 1988). 
From the variations in the responses given by respondents who were interviewed concerning causes of disabilities, one can tell that most of the respondents had limited levels of understanding of the causes of disability. A possible reason why most parents/caregivers hardly knew the cause of disability could have been due to the level of education, because none of the respondents had a sound education.

The results of the study showed that some parents felt that they were completely responsible for the disability of their child, others felt some responsibility, and only one felt that they were not responsible for the disability of their child. These results can be compared with earlier studies which have shown that one of the most frequently cited reactions commonly attributed to parents of disabled children is that of guilt (Leavitt, 1992; Pimm, 1996.) Lack of adequate information regarding the child's disability, can be a major source of stress in most families. Therefore, it is relevant that causes of disabilities are explained to parents of disabled children in order to reduce the possibilities of stress.

Much has been written about the role of professionals in dealing with families who are stressed (Cherry, 1989). Although health professionals may not work with families directly in coping with some of their perceptions, they can play a major role in preventing unnecessary stressful situations by providing adequate information about the child's condition in terms of aetiology and the likely prognosis. Helping and working with such families requires a multidisciplinary effort. Effective communication among families, professionals and knowledge of community resources will therefore, be crucial for the amelioration of perceptions which may cause stress in families caring for children with cerebral palsy.

\section{REFERENCES}

Abrams, E. \& Goodman, J. (1998). Diagnosing developmental problems in children: Parents and professionals negotiate bad news. Journal of Paediatric Psychology, 23 (2):, 87-98.

Adams, G.L. (1992). Referral advise given by physicians. Mental Retardation, 20: 16-20.

Cherry, D. B. (1989). Stress coping in families with ill or disabled children: Application of the model to paediatric therapy. Physiotherapy and Occupational Therapy Paediatrics, 9 (2): 11-32.
Foster, G. M. \&Anderson, B. G. (1978). : Medical Anthropology: Ethnomedicine. Alfred Knopf, New York.

Kleinman, A. (1980). Patients and healers in the context of culture. University of California Press: Berkley, California and London.

Leavitt, R. L. (1992). Disability and Rehabilitation in rural Jamaica: An Ethnographic study. Associated University Press, London and Toronto.

Lynch, E., \& Staloch, N. (1988). Parental perceptions of physicians' communication in the information process. Mental Retardation, 26: 77-8I.

Pimm, P. L. (1996).Some of the implications of caring for a child or adult with cerebral palsy. British journal of Occupational Therapy, 59 (7): 335-340.

Reis, R. (1992). Heit Ziektestempel in Swaziland. Anthropologosche Verkenningen, 3: 27-43.

White Paper on an Intergrated National Disabilituy Strategy (November 1997). Office of the Deputy President T. M. Mbeki, Republic of South Africa.

WHO (1980). International Classification of Impairment, Disability and Handicap. Geneva.

WHO (1997). The International Classification of Impairments, Activities and Participation: a manual of dimensions of disablement and functioning, "beta-1". Geneva

$\frac{\text { BOOK }}{\text { REVIEW }}$

\section{PNF in Practice - An Illustrated Guide}

\section{2nd revised edition}

Springer-Verlag

Susan S Adler, Dominiek Beckers, Math Buck

$\mathrm{B}$ ooks on PNF tend to be very technical, but I was pleasantly surprised when reviewing this book. It is easy to follow with plenty of illustrations to assist the reader in understanding the text. The authors have emphasised that it is a practical techniques book using visual aids rather than words to describe actions. I did find that it had little theory, and as suggested, further reading is necessary in this area for postgraduates. Certainly this book is more than adequate for undergraduates and for the generalist who wants to have a reference book handy. It has all the basics - principles, special techniques (not all - I felt timing for emphasis was not comprehensively explained), upper and lower limb patterns, neck and trunk patterns and face patterns. It gives good alternate staring positions with both new and old terminology. I found that it not only incorporated both upper and lower limb patterns with mat work (alternate positions) and special techniques, but also listed all the muscles used in a particular pattern. I find the presentation encouraging as generally students have difficulty in integrating different concepts. I was also pleased to see that precautions were specially mentioned in block form.

I have a major concern that this book lacks an index of subject matter. I would however definitely recommend this book to the undergraduate and the qualified generalist.

Jessico Lund 